\title{
Scission of Diblock Copolymers into their Consituent Blocks
}

Serkan Yurt ${ }^{\S}$, Uche K. Anyanwu ${ }^{\S}$, Jocelyn R. Scheintaub, E. Bryan Coughlin ${ }^{\S}$ and D. Venkataraman ${ }^{\S *}$

Department of Chemistry and Department of Polymer Science and Engineering, University of Massachusetts Amherst, Amherst, MA 01003

\section{SUPPORTING INFORMATION}

\footnotetext{
$\S$ Department of Chemistry

" Department of Polymer Science and Engineering
} 
General. All of the reactions, unless otherwise noted, were conducted under an inert atmosphere of argon. MPEG $\left(\mathrm{M}_{\mathrm{n}}=5000\right)$ purchased from commercial sources was used without further purification. Styrene and bromostyrene were freshly distilled over calcium hydride prior to use. MPEG-mesylate was prepared according to the literature ${ }^{1}$ except that we used tri- n-octylamine instead of tri-ethylamine as the base. All solvents, (THF and toluene), unless otherwise noted, were distilled from a Na/benzophenone ketyl and stored under inert atmosphere. Purification was performed by flash chromatography using ICN Flash Silica Gel, 230-400 mesh. Reported yields are the isolated yields of the characterized compounds, deemed pure by elemental analyses, ${ }^{1} \mathrm{H}$ NMR spectra were recorded on a $400 \mathrm{MHz}$ spectrometer. Chemical shifts were reported in ppm downfield from TMS as an internal standard where available. The peak patterns are indicated as follows: s, singlet; d, doublet; t, triplet; dd, doublet of doublets; br, broad; and m, multiplet. The coupling constants, $J$, are reported in Hertz $(\mathrm{Hz})$. The molecular weights of polymers were characterized by Gel Permeation Chromatography using a flow rate of $1 \mathrm{~mL} \mathrm{~min}$ (DMF with $^{-1}$ (DM) $0.01 \mathrm{M} \mathrm{LiCl}$ as the solvent at $50^{\circ} \mathrm{C}$ ), cross-linked polystyrene column (PL GEL) and a RI detector (wellchrom K-2301). The UV/Vis spectra was recorded using a Shimadzu UV2401PC with a photomultiplier R-928 detector and a 50W halogen and deuterium lamps.

1-[1-(4-Bromo-phenyl)-ethoxy]-2,2,6,6-tetramethyl-piperidine (1) : To a solution of p-bromo styrene $(0.26 \mathrm{ml}, 2 \mathrm{mmol})$ and TEMPO $(0.318 \mathrm{~g}, 2 \mathrm{mmol})$ in 1:1 toluene/ethanol (14 $\mathrm{mL})$ was added [N, N' -bis(3,5-di-tert-butylsalicylidene)-1,2-cyclohexanediaminato] manganese (III) chloride (Jacobsen's catalyst) $(0.19 \mathrm{~g}, 0.3 \mathrm{mmol})$ followed by di-tertbutyl peroxide $(0.36 \mathrm{~mL}, 2 \mathrm{mmol})$ and sodium borohydride $(0.154 \mathrm{~g})$. The reaction mixture was then stirred in air at $23{ }^{\circ} \mathrm{C}$ for $22 \mathrm{~h}$. the solvent then removed under vacuo and $\mathrm{CH}_{2} \mathrm{Cl}_{2}$ was added to the resultant residue. The solution was then transferred into a seperatory funnel and washed with water. The aqueous extracts were collected and any residual organic components were extracted in $\mathrm{CH}_{2} \mathrm{CL}_{2}$. The combined organic layers were dried with anhydrous sodium sulfate, evaporated to dryness, and the crude product was purified by flash column chromatography eluting with 3:7 $\mathrm{CH}_{2} \mathrm{Cl}_{2}$ /hexanes. The $p$-bromo alkoxyamine, was recrystallized from acetonitrile to get pure, white crystalline solid $(0.241 \mathrm{~g}, 35.41 \%)$. ${ }^{1} \mathrm{H}$ NMR $\left(400 \mathrm{MHz}, \mathrm{CDCl}_{3}\right) \delta=7.39-7.41\left(\mathrm{~d}, J=8.4 \mathrm{~Hz}, 2 \mathrm{H}, \mathrm{H}_{\mathrm{Ar}}\right), 7.16-7.18\left(\mathrm{~d}, J=8.4 \mathrm{~Hz}, 2 \mathrm{H}, \mathrm{H}_{\mathrm{Ar}}\right)$, 4.69-4.74 (q, $J=6.7 \mathrm{~Hz}, 1 \mathrm{H},-\mathrm{CH}), 1.41-1.43$ (d, $J=6.7 \mathrm{~Hz}, 3 \mathrm{H},-\mathrm{CH}_{3}$ ), 1.30-1.53 (m,(br) $6 \mathrm{H}$, $\mathrm{CH}_{2}$ ), 0.620 .99 , 1.13, 1.25 (each s, $12 \mathrm{H},-\mathrm{CH}_{3}$ ); Anal. Calcd. for $\mathrm{C}_{17} \mathrm{H}_{26} \mathrm{BrNO}$ : C, 60.00; $\mathrm{H}$, 7.70; Br, 23.48; N, 4.12; Found: C, 60.07; H, 7.80; N, 4.16.

Diphenyl-\{4-[1-(2,2,6,6-tetramethyl-piperidin-1-yloxy)-ethyl]-phenyl\}-methanol (2) : To a stirring solution of 1-[1-(4-Bromo-phenyl)-ethoxy]-2,2,6,6-tetramethyl-piperidine (0.586 g, $1.717 \mathrm{mmol})$ in THF $(5 \mathrm{~mL})$ at $-78{ }^{\circ} \mathrm{C}$, was added $n$-butyl lithium (1.61 mL, $\left.2.58 \mathrm{mmol}\right)$, dropwise via a syringe and needle. The resultant pale yellow solution was allowed to stir for 30 minutes after which it was transferred, via a syringe and needle, to a stirring solution of benzophenone $(0.314 \mathrm{~g}, 1.717 \mathrm{mmol})$ in THF $(3 \mathrm{~mL})$ at $-78{ }^{\circ} \mathrm{C}$. The reaction mixture turned bluish-green and then it was run for 1 hour. The reaction mixture was concentrated in vacuo and the oily residue was taken up in $\mathrm{CH}_{2} \mathrm{Cl}_{2}(25 \mathrm{~mL})$, acidified with acetic acid/ $\mathrm{H}_{2} \mathrm{O}(100 \mathrm{~mL})$, washed with saturated

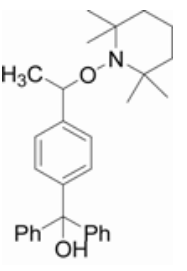
$\mathrm{NaCl}_{(\mathrm{aq})}$ solution and evaporated to dryness. Then the resultant white solid was washed with hexanes and recrytallized from ethyl acetate to afford white crystals of $2 .{ }^{1} \mathrm{H}$ NMR (400 MHz, 
$\left.\mathrm{CD}_{2} \mathrm{Cl}_{2}\right) \delta=7.24-7.50(\mathrm{~m}), 6.20-6.24(\mathrm{q}, J=6.4 \mathrm{~Hz}), 2.94(\mathrm{~s}), 1.72-1.74(\mathrm{~d}, J=6.5 \mathrm{~Hz}), 1.45-$ 1.74 (m), 1.14, 1.23, 1.42, 1.85 (each s); HRMS Calcd. for $\mathrm{C}_{30} \mathrm{H}_{37} \mathrm{NO}_{2}, \mathrm{~m} / \mathrm{z}$ : 444.29; Found(by FAB): 444.29

MPEG-supported trityl-TEMPO initiator: Into a Schlenk flask was placed a magnetic stirbar, diphenyl-\{4-[1-(2,2,6,6-tetramethyl-piperidin-1-yloxy)-ethyl]-phenyl $\}$ methanol (2) (0.445 g, $1 \mathrm{mmol})$, sodium hydride (95 $\mathrm{wt} \%$ suspension in mineral oil) $(0.078 \mathrm{~g}, 3.0 \mathrm{mmol})$ and THF $(15 \mathrm{~mL})$. The suspension was heated to $70{ }^{\circ} \mathrm{C}$ for $70 \mathrm{~h}$ after which a solution of $\mathrm{MPEG}_{5000}$ mesylate $(2.3 \mathrm{~g})$ in THF $(10 \mathrm{~mL})$ was added to the reaction mixture and it was allowed to stir at $70{ }^{\circ} \mathrm{C}$. After $24 \mathrm{~h}$, the reaction mixture was left to cool to room temperature, filtered through a pad of celite and concentrated in vacuo. The oily residue

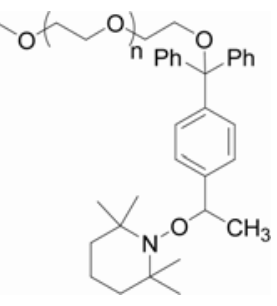
was added drop-wise to stirring diethyl ether at $0{ }^{\circ} \mathrm{C}$ and the precipitate taken up in a minimal amount of $\mathrm{CH}_{2} \mathrm{Cl}_{2}$, and reprecipitated from diethyl ether ( 2 more times). The solid obtained (1.5 g) was dried under vacuum. The disappearance of the mesylate methyl peak at $3.08 \mathrm{ppm}$ showed that the reaction was complete. ${ }^{1} \mathrm{H}$ NMR $\left(400 \mathrm{MHz}, \mathrm{CD}_{2} \mathrm{Cl}_{2}\right) \delta=7.24-7.47\left(\mathrm{~m}, \mathrm{H}_{\mathrm{Ar}}\right), 4.76-4.82$ (q), 3.34 (s, $\mathrm{CH}_{3}$-O-PEG-), 3.41-3.79 (-PEG-), 1.45-1.47 (d, $\left.J=6.7 \mathrm{~Hz},-\mathrm{CH}_{3}\right), 0.65,1.02,1.15$, 1.27, (each s (br), $-\mathrm{CH}_{3}$ ).

Nitroxide Mediated “Living” Free radical Polymerization: The typical procedure for LFRP of the $\mathrm{MPEG}_{5000}$-supported initiator was as follows: To a solution of $\mathrm{MPEG}_{5000}$-supported initiator $(0.14 \mathrm{~g}$, ) in degassed toluene $(1.0 \mathrm{~mL})$, was added styrene $(0.6 \mathrm{~mL}$, density $0.906 \mathrm{~g} / \mathrm{mL})$. The reaction mixture was heated to $130{ }^{\circ} \mathrm{C}$ for $12 \mathrm{~h}$. Then, cooled to room temperature and added drop-wise to stirring methanol to precipitate the PS- $b$-MPEG diblock copolymer, as a white solid. It was characterized by $\mathrm{GPC}$ as $\mathrm{M}_{\mathrm{n}}=31600, \mathrm{M}_{\mathrm{w}}=37300$, PDI $=1.18$ (standard is PS in GPC).

Acid Cleavage of PS-b-MPEG in solution : The cleavage was as follows : In a solution of PS$b$-MPEG $\left(\mathrm{M}_{\mathrm{w}}\right.$ of 31441 by end group analysis in ${ }^{1} \mathrm{H}-\mathrm{NMR}$ in $d_{2}$-DCM $)$ in $d_{8}$-toluene $(2.4 \mathrm{~mL})$, was added $d_{1}$-trifluoroacetic acid (TFA) $(1 \mathrm{~g})$. Upon addition of TFA, the color of the solution changed to orange (see Figure S1). This solution was allowed to stir for approximately 20 minutes after which $\mathrm{D}_{2} \mathrm{O} / d_{1}$-TFA $(1 \mathrm{~mL} / 1 \mathrm{~g})$ was added to the reaction. The aqueous layer was separated and used for ${ }^{1} \mathrm{H}-\mathrm{NMR}$ analysis. The organic layer was washed with water $(4 \mathrm{x} 100$ $\mathrm{mL}$ ) and then with saturated $\mathrm{NaCl}_{\text {(aq.) }}(25 \mathrm{ml})$. The ${ }^{1} \mathrm{H}-\mathrm{NMR}$ (in $d_{8}$-toluene) of organic and aqueous layers is shown in Figures S2 and S3. Toluene was then removed under vacuo and the resultant residue was used for GPC analysis and for recording ${ }^{1} \mathrm{H}-\mathrm{NMR}$ in $\mathrm{CD}_{2} \mathrm{Cl}_{2}$. The $\mathrm{M}_{\mathrm{w}}$ obtained for the PS part both in ${ }^{1} \mathrm{H}-\mathrm{NMR}$, by end group analysis, and in GPC were in good agreement $\left(\mathrm{M}_{\mathrm{w}}\right.$ of 23801 by GPC, $\mathrm{M}_{\mathrm{w}}$ of 25875 by end group analysis in ${ }^{1} \mathrm{H}-\mathrm{NMR}$ in PS- $b$ MPEG diblock copolymer).

As a control experiment $\mathrm{MPEG}_{5000}$ was dissolved in $\mathrm{D}_{2} \mathrm{O}(1 \mathrm{~mL})$, added $\mathrm{d}_{1}-\mathrm{TFA}$, stirred for $10 \mathrm{~min}$ and ${ }^{1} \mathrm{H}-\mathrm{NMR}$ was obtained directly from that solution. The chemical shifts of the peaks obtained where similar to the peaks obtained from the aqueous layer of the cleavage experiment. 


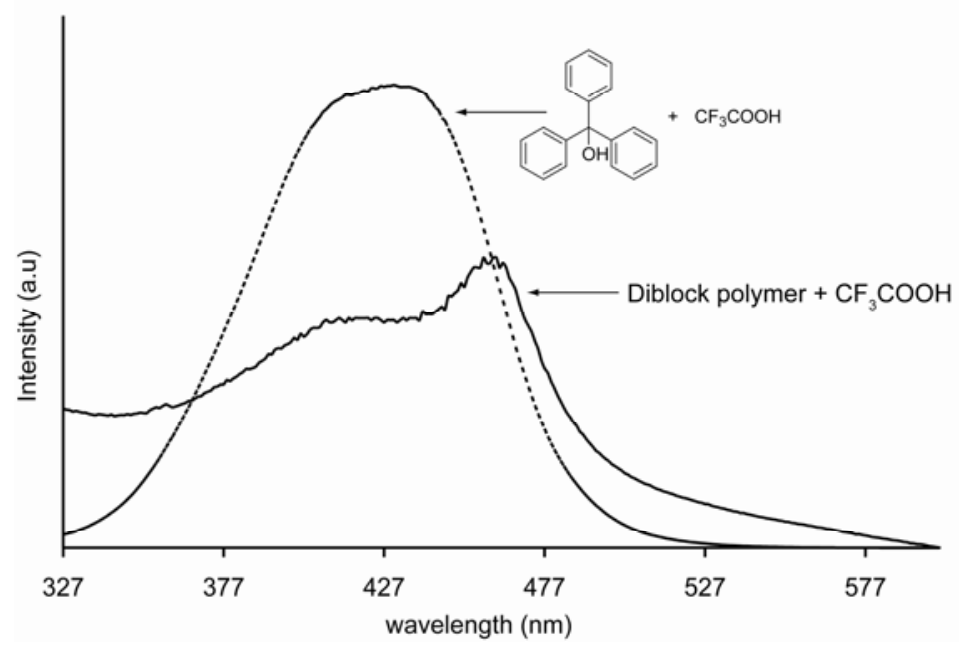

Figure S1. UV-vis absorption spectra of the diblock polymer with trifluoroacetic acid (solid line) and triphenylmethanol with trifluoroacetic acid (dashed line). The absorptions indicate the formation of the triphenylmethyl cation. The toluene background was subtracted from the spectra.

(b) Organic Phase

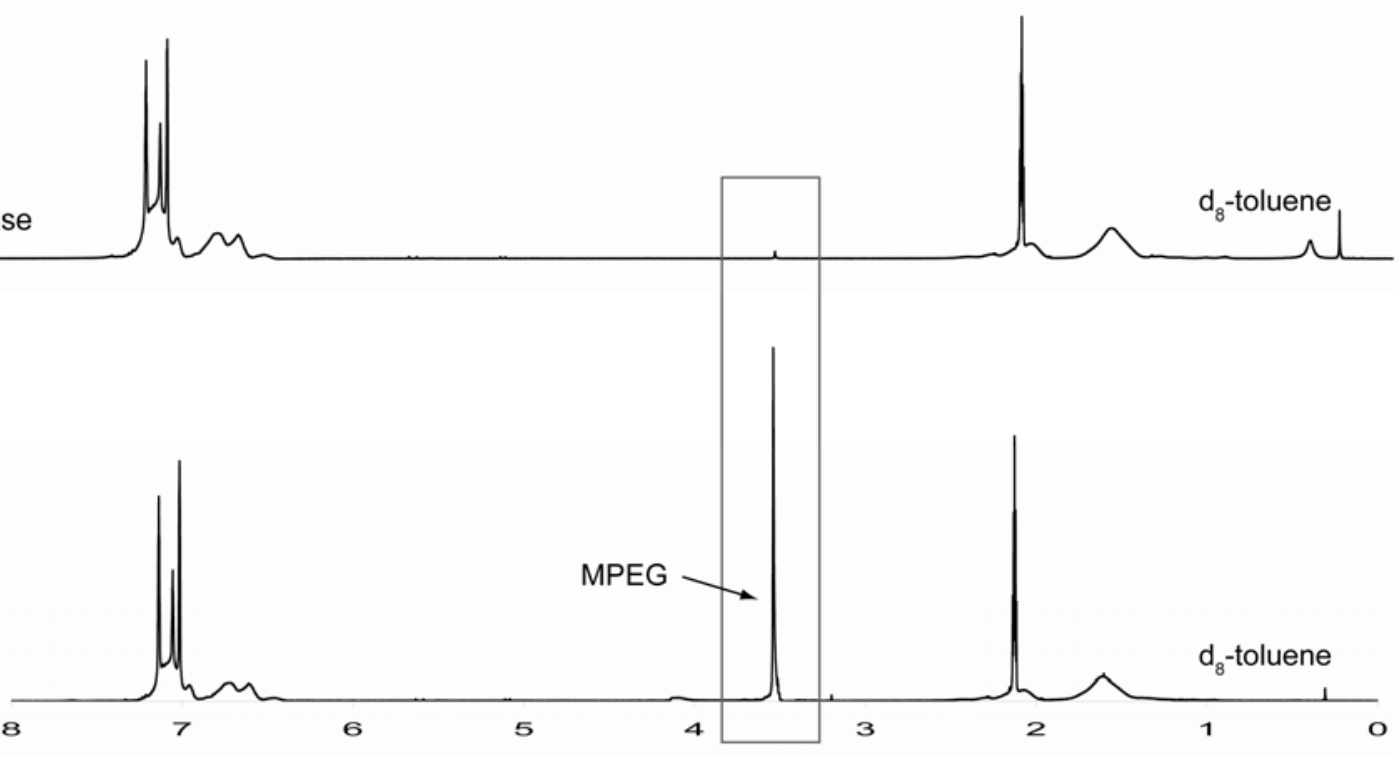

Figure S2. ${ }^{1} \mathrm{H}$ NMR of the diblock copolymer (in $d_{8}$-toluene) and the organic layer(in $d_{8}$-toluene) 


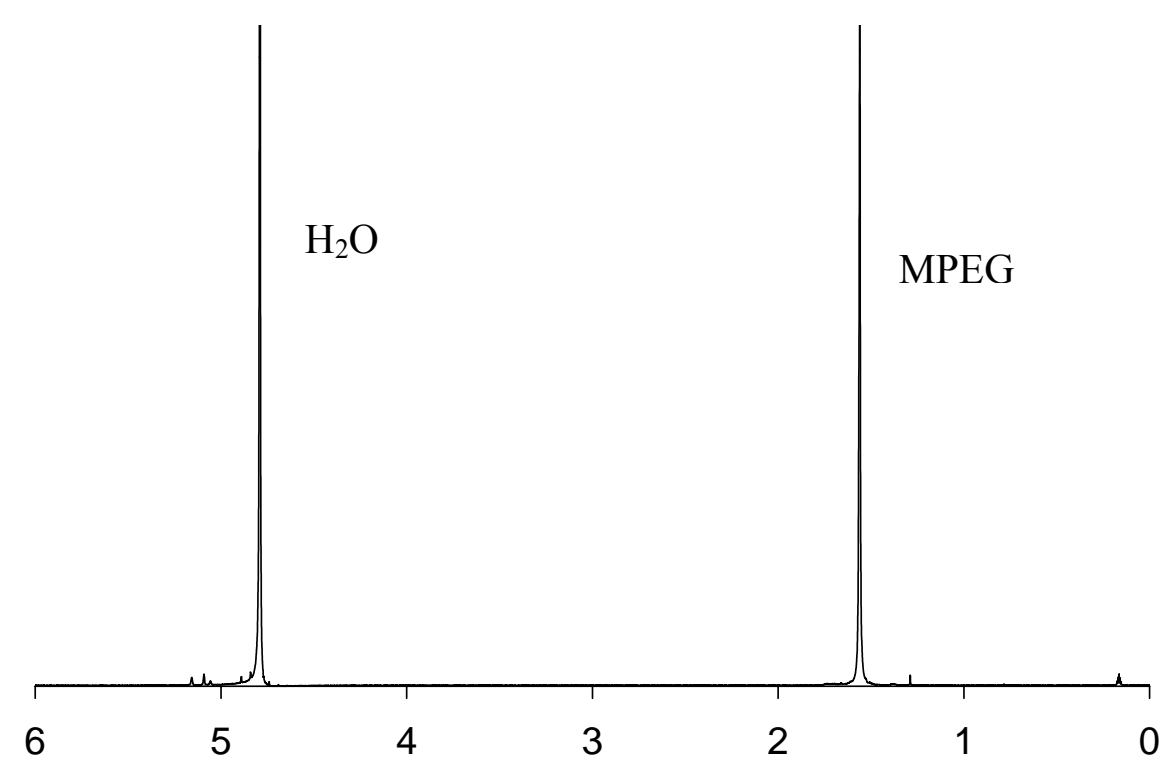

Figure S3. ${ }^{1} \mathrm{H}$ NMR of the aqueous layer in $\mathrm{D}_{2} \mathrm{O}$ showing the peaks attributable to MPEG.

To confirm that MPEG was intact during the reaction, the MPEG-b-PS diblock copolymer with the $\mathrm{M}_{\mathrm{w}}$ of 31400 was dissolved in toluene (59 mg / $3 \mathrm{~mL}$ ) in a test tube and to this solution added TFA $(0.7 \mathrm{ml})$. The color of the solution turned to orange-like color. It was stirred for 5 minutes and the reaction was stopped by washing first with water $(0.5 \mathrm{~mL})$ then with saturated $\mathrm{NaCl}_{(\text {aq.) }}(2 \times 0.5 \mathrm{~mL})$. Organic layer, containing both PS and MPEG, was transferred to a flask and the solvent was removed under vacuo. After the cleavage of diblock copolymer, It is not easy to see MPEG portion clearly, by GPC, in the presence of excess amount of PS portion. Therefore to remove most of the PS portion, the resultant polymer was washed out with cyclohexane $(3 \times 2 \mathrm{~mL})$, which is a good solvent for PS but not for MPEG. GPC showed bimodal peaks for the residues left in the flask, corresponding to MPEG and PS portions of diblock copolymer obtained before.

Acid Cleavage of MPEG-b-PS in solid state: A solution of PS- $b$-MPEG- (26 mg) in chloroform $(1 \mathrm{~mL})$ was drop cast on two glass plates, each with $0.5 \mathrm{ml}$ of solution. Both slides were dried under ambient conditions for more than 8 hours and then they were placed on top of the vials. One of the vials placed in a larger vial containing TFA. The larger vial was sealed with a screw cap. After 1 hour it was taken out of chamber, washed out with water $(3 \times 10 \mathrm{~mL})$, dried and GPC spectrum was obtained for that sample. The color of the thin film turned, from orange, back to white when it was washed with water. The GPC data of the resultant polymer $\left(\mathrm{M}_{\mathrm{w}}\right.$ of 23577) indicated the loss of the MPEG block (Figure S4). As a control, the other vial was placed under ambient conditions for two days and then washed with water. The GPC of the residue did not show any change in the molecular weight (Figure S5). 


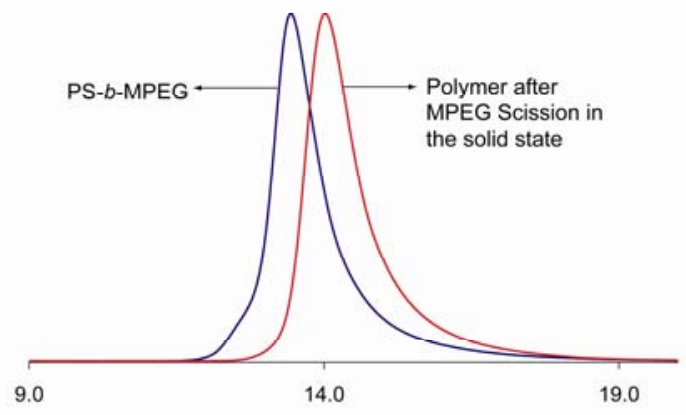

Figure S4: GPC traces of the diblock copolymer and the polymer after exposure of the thin film to trifluroacetic acid vapors.

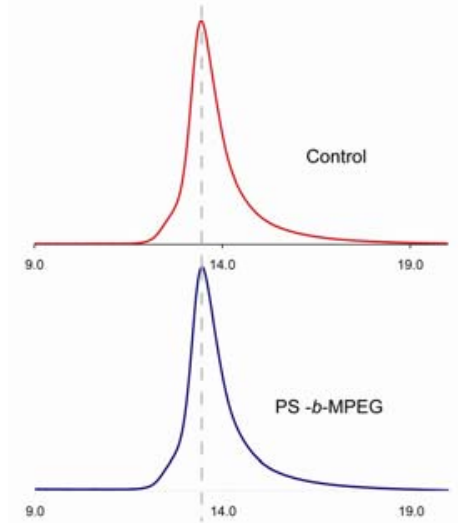

Figure S5: GPC traces of the diblock copolymer and the polymer thin film exposed to ambient atmosphere. 


\section{References:}

(1) Zhao, X. Y.; Janda, K. D. Tetrahedron Lett. 1997, 38, 5437-5440. 